\title{
Impact of Psychological Status on Adherence to Treatment Following Coronary Artery Bypass Grafting
}

\author{
Svetlana Pomeshkina ${ }^{1}$, Anton Solodukhin ${ }^{1,2}$, Anastasia Inozemtseva ${ }^{1}$, Mikhail Yanitskiy $^{2}$, Andrey \\ Seryy $^{2, *}$ and Olga Barbarash ${ }^{1}$ \\ ${ }^{1}$ Federal State Budgetary Institution, "Research Institute for Complex Issues of Cardiovascular \\ Diseases”, Kemerovo, Russia \\ ${ }^{2}$ Kemerovo State University, Kemerovo, Russia \\ *Corresponding Author
}

Keywords: Coronary Bypass Grafting, Coping Strategies, Patients' Perception of Disease, Adherence.

Abstract: the study was aimed at determining the associations between patients' perception of illness, coping-strategies to overcome disease-related stress and adherence to treatment in patients following coronary artery bypass grafting (CABG). 378 men after elective CABG were recruited in the study. Patients were interviewed 5-7 days before CABG and 6 months after by a health psychologist. The clinical status was assessed in all patients. All relevant data in the in-patient and outpatient medical records were reviewed. All recruited subjects responded on the Personal Questionnaire of the Bekhterev Institute (PQBI) before CABG. The coping strategies were assessed with the Ways of Coping Questionnaire developed by Lazarus and Folkman. According to the results of the study, patients' adherence to treatment declined six months after CABG. Those patients who remained adherent to therapy had harmonious and ergonomic models of preoperatively illness perception. In addition, patients who were adherent to treatment were more likely to use positive coping strategies (problem solving planning, taking responsibility, and self-control). Analysis of the correlation between patients' perception of the disease and coping strategies established the negative correlations between harmonious model and emotion-focused coping, i.e. escape-avoidance strategies $(r=-0.3, p=0.002)$, ergonomic model and escape-avoidance coping $(r=-0.3, p=0.006)$ and cognitive distancing $(r=-0.19, p=0.001)$. A positive association between anxious illness perception model and escape-avoidance strategies $(\mathrm{r}=$ $0.31, \mathrm{p}=0.001$ ) has been found. Thus, patients' perception of illness and coping skills in the preoperative period of $\mathrm{CABG}$ allows predicting the poor adherence to treatment in the postoperative period.

\section{Introduction}

The causes leading to poor patients' adherence to therapy is of paramount importance for clinical psychologists and healthcare providers. The measures to increase long-term patients' adherence remain ineffective [1]. Recent studies distinguish five major groups of factors that affect patients' behavior and commitment: (1) socio-economic factors; (2) therapy-related factors; (3) physicians- 
related factors; (4) physical condition of the patient, and (5) psychological state of the patient.

Patients attitude to the prescribed therapy is driven by behavioral patterns, emotional identity, his emotional mood, coping behavior, as well as patients' perception of the disease and their axiology profile. The patient's motivation to start and continue treatment depends on his perception of the disease, i.e. the sum of his feeling, concerns and experience that evoked when the disease is diagnosed [2]. The patient is ready to cooperate with a physician and adhere to prescribed treatment only if he does not ignore the presence of the disease and understands its health-related consequences. If the patient has positive illness perception model (understanding the disease, its causes and consequences), he will demonstrate better long-term adherence to therapy. There is some evidence suggesting that coping strategies may influence patients' adherence to prescribed therapy [3]. Coping strategy is defined as an activity aimed at maintaining a balance between the demands of the environment and human resources that allow satisfying these requirements [4]. The purpose of this study was to identify the links between patients' perception of the disease, coping strategies and adherence to therapy in patients undergoing coronary artery bypass grafting.

\section{Initial Data}

All subjects gave written informed consent to participate in the study. 378 male patients with stable coronary artery disease, aged 41 to 77 years, referred to elective on-pump CABG were recruited into the study. The inclusion criteria were as follows: male sex, elective CABG and written informed consent to participate in the study. The exclusion criterion was a patient's refusal to participate in the study.

Clinical and demographic data of the patients recruited in the study are presented in Table 1.

Table 1. Clinical and demographic data of the patients referred to elective CABG

\begin{tabular}{|l|c|}
\hline Parameters & $\mathbf{n = 3 7 8}$ \\
\hline Age, years & $59,9 \pm 6,9$ \\
\hline Prior myocardial infarction, n (\%) & $215(57)$ \\
\hline Duration of CAD, years & $3(1 ; 9)$ \\
\hline Mean functional class of angina & $2,03 \pm 0,36$ \\
\hline Mean NYHA functional class & $1,98 \pm 0,42$ \\
\hline Arterial hypertension, n (\%) & $340(90)$ \\
\hline Diabetus mellitus, n (\%) & $42(11)$ \\
\hline Left ventricular ejection fraction (\%) & $56,9 \pm 6,8$ \\
\hline
\end{tabular}

The study was performed in accordance with Good Clinical Practice and the principles of the World Medical Association Helsinki Declaration "Ethical Principles for Medical Research Involving Human Subjects". The study protocol was approved by the local Ethics Committee of the Research Institute for Complex Issues of Cardiovascular Diseases.

The psychological and clinical status of all recruited patients was conducted 5-7 days before the CABG and 6 months after it. Patients' medical and outpatient records were used to analyze laboratory and instrumental data obtained during the in-hospital period and after their discharge. The adherence of patients to treatment was evaluated using a self-developed questionnaire, containing the individual assessment of risk factors for developing $\mathrm{CAD}$, therapy received before 
surgery and within 6 months after it. All data were obtained directly from the recruited patients. Patients' perception of illness was estimated with the Types of Attitude Towards the Disease Questionnaire, developed by A.E. Lichko. A more detailed description of this approach was presented by Vasserman et al. [5]. Coping strategies routinely used by cardiac patients were estimated with S. Folkman and R.S. Lazarus' The Ways of Coping Questionnaire [6]. According to patients' adaptation to the in-hospital settings before elective CABG, all coping strategies were divided into positive, negative and those aimed at seeking social support to overcome stress.

Positive coping strategies include problem solving planning, taking responsibility, self-control.

Negative coping strategies include confrontive coping, distancing, escape-avoidance coping and positive reappraisal.

Of note, seeking social support did not exclude patients' cooperation with medical personnel, but implies the solution of any problems related to the treatment process with the help of people surrounding a patient, including physicians and nurses. Therefore, seeking social support coping was assigned to a neutral model of behavior. The mean in-hospital period in the total cohort was $11 \pm 2$ days. All patients were recommended to control common modifiable risk factors (cholesterol level, weight, hypertension, smoking) upon the discharge. All of them underwent patient educational course on active lifestyle and adherence to the prescribed therapy. The statistical analysis was performed with the commercially available software package Statistica 10.0 (StatSoft, Tulsa, OK, USA). The Shapiro-Wilk test was used to measure the normality of the distribution. Continuous variables with normal distribution are presented as the mean (M) and standard deviation (SD). Variables with skewed distribution are presented as median $(\mathrm{Me})$ and the interquartile range $\mathrm{Me}(25 ; 75) . \mathrm{P}<0.05$ was considered statistically significant.

\section{Development of statistical models}

The analysis of modifiable cardiovascular risk factors established $83(22 \%)$ patients to have obesity with body mass index (BMI) $\geq 30 \mathrm{~m}^{2} / \mathrm{kg}$ before CABG. However, their number did not change within the follow-up period. 6 months after CABG, 166 (44\%) patients had elevated BMI, $140(37 \%)$ patients had decrease BMI, and $72(19 \%)$ reported similar values. The mean BMI in patients after CABG did not change significantly (from $28.1 \pm 3.4$ to $27.9 \pm 3.4 \mathrm{~kg} / \mathrm{m}^{2}$ ). Of 110 (29\%) active smokers, only 24 (6.4\%) gave up smoking in the end of the follow-up period. The mean total cholesterol level and low-density lipoprotein level significantly reduced within 6 months after CABG (from $4.9 \pm 1.5$ to $3.0 \pm 1.1 \mathrm{mmol} / \mathrm{L}, \mathrm{p}=0.00$; from $3.0 \pm 1.1$ to $2.4 \pm 0.6 \mathrm{mmol} / \mathrm{L}$, p $=0.00$, respectively). However, only $150(39.7 \%)$ patients achieved the target total cholesterol level $(<4.0 \mathrm{mmol} / \mathrm{L})$, and $66(17.5 \%)$ patients - the target LDL level. Of the total cohort, $91(24 \%)$ patients monitored carefully their lipid profile within the follow-up period. $257(68 \%)$ patients achieved the target blood pressure levels within six months after surgery.

The analysis of adherence to prescribed therapy within 6 months after CABG reported a significant increase in the number of patients taking the recommended drugs: ACE inhibitors (angiotensin converting enzyme inhibitor) / ARB (angiotensin receptor blocker) - from $138(36.5 \%)$ to $234(62 \%)$ patients, antiplatelet agents - from $185(49 \%)$ to $253(67 \%)$ patients, statins - from 166 $(44 \%)$ to $268(71 \%)$ patients, $\beta$-adrenoblockers (BAB) - from $215(57 \%)$ to $329(87 \%)$ patients. Only 268 (71\%) patients took 3-4 component therapy within 6 months after CABG.

The next stage included the assessment of the psychological status of CAD patients, including patients' perception of illness and their coping skills in relation to their adherence to treatment. We found that patients with reduced or unchanged BMI, those who quit smoking and regularly took 3-4 component therapy, as well as those who achieved the target blood pressure values in the follow-up, commonly had harmonic, ergonomic and a combination of harmonic and ergonomic illness 
perception models. Isolated anosognosic model or combined with a harmonious model was observed in patients who did not follow medical and non-medical therapy (Tables 2-6).

Table 2. Prevalence of illness perception models depending on the presence of compensation of BP.

\begin{tabular}{|l|c|c|c|}
\hline \multirow{2}{*}{ Illness perception model } & \multicolumn{3}{|c|}{ Compensation of BP } \\
\cline { 2 - 4 } & yes & no & $\mathrm{p}$ \\
\hline Harmonious & $42(11 \%)$ & $18(5 \%)$ & 0,04 \\
\hline Ergonomic & $24(6 \%)$ & $6(2 \%)$ & 0,28 \\
\hline Anosognosic & $24(6 \%)$ & $12(3 \%)$ & 0,49 \\
\hline Anxious Hypochondriacal & $12(3 \%)$ & $12(3 \%)$ & 0,67 \\
\hline Harmonious Ergonomic Anosognosic & $114(30 \%)$ & $60(16 \%)$ & 0,03 \\
\hline Harmonious Anosognosic & $24(6 \%)$ & 0 & 0,04 \\
\hline Ergonomic Anosognosic & $6(2 \%)$ & $6(2 \%)$ & 0,48 \\
\hline Anosognosic Hypochondriacal & $6(2 \%)$ & 0 & 0,48 \\
\hline
\end{tabular}

Table 3. Prevalence of illness perception models depending on the presence of increase in BMI.

\begin{tabular}{|l|c|c|c|}
\hline \multirow{2}{*}{ Illness perception model } & \multicolumn{3}{|c|}{ An increase in BMI } \\
\cline { 2 - 4 } & no & yes & $\mathrm{p}$ \\
\hline Harmonious & $54(14 \%)$ & $6(2 \%)$ & 0,004 \\
\hline Ergonomic & $24(6 \%)$ & $6(2 \%)$ & 0,28 \\
\hline Anosognosic & $6(2 \%)$ & $30(8 \%)$ & 0,10 \\
\hline Anxious Hypochondriacal & $18(5 \%)$ & $6(2 \%)$ & 0,44 \\
\hline Harmonious Ergonomic Anosognosic & $90(24 \%)$ & $84(22 \%)$ & 0,86 \\
\hline Harmonious Anosognosic & 0 & $24(6 \%)$ & 0,04 \\
\hline Ergonomic Anosognosic & $6(2 \%)$ & $6(2 \%)$ & 0,61 \\
\hline Anosognosic Hypochondriacal & $6(2 \%)$ & 0 & 0,48 \\
\hline
\end{tabular}

Table 4. Prevalence of illness perception models depending on the presence of smoking after CABG.

\begin{tabular}{|l|c|c|c|}
\hline \multirow{2}{*}{ Illness perception model } & \multicolumn{3}{|c|}{ Smoking after CABG } \\
\cline { 2 - 4 } & yes & no & $\mathrm{p}$ \\
\hline Harmonious & $12(3 \%)$ & $48(12 \%)$ & 0,03 \\
\hline Ergonomic & 0 & $30(8 \%)$ & 0,01 \\
\hline Anosognosic & $30(8 \%)$ & $6(2 \%)$ & 0,1 \\
\hline Anxious Hypochondriacal & $6(2 \%)$ & $18(5 \%)$ & 0,44 \\
\hline Harmonious Ergonomic Anosognosic & $36(9 \%)$ & $138(36 \%)$ & 0,00 \\
\hline Harmonious Anosognosic & $12(3 \%)$ & $12(3 \%)$ & 0,68 \\
\hline Ergonomic Anosognosic & $6(2 \%)$ & $6(2 \%)$ & 0,61 \\
\hline Anosognosic Hypochondriacal & $6(2 \%)$ & 0 & 0,48 \\
\hline
\end{tabular}


Table 5. Prevalence of illness perception models depending on the presence of adherence to medical therapy

\begin{tabular}{|l|c|c|c|}
\hline \multirow{2}{*}{ Illness perception model } & \multicolumn{3}{|c|}{ Adherence to medical therapy } \\
\cline { 2 - 4 } & no & yes & $\mathrm{p}$ \\
\hline Harmonious & $6(2 \%)$ & $54(14 \%)$ & 0,004 \\
\hline Ergonomic & $6(2 \%)$ & $24(6 \%)$ & 0,28 \\
\hline Anosognosic & $18(5 \%)$ & $18(5 \%)$ & 0,74 \\
\hline Anxious Hypochondriacal & $12(3 \%)$ & $12(3 \%)$ & 0,67 \\
\hline Harmonious Ergonomic Anosognosic & $60(16 \%)$ & $114(30 \%)$ & 0,03 \\
\hline Harmonious Anosognosic & $6(2 \%)$ & $18(5 \%)$ & 0,44 \\
\hline Ergonomic Anosognosic & 0 & $12(3 \%)$ & 0,24 \\
\hline Anosognosic Hypochondriacal & 0 & $6(2 \%)$ & 0,48 \\
\hline
\end{tabular}

Table 6. Prevalence of illness perception models depending on the presence of achievement of total cholesterol target values.

\begin{tabular}{|l|c|c|c|}
\hline Illness perception model & \multicolumn{3}{|c|}{ Achievement of total cholesterol target values } \\
\hline & no & yes & $\mathrm{p}$ \\
\hline Harmonious & $48(13 \%)$ & $12(3 \%)$ & 0,03 \\
\hline Ergonomic & $24(6 \%)$ & $6(2 \%)$ & 0,28 \\
\hline Anosognosic & $24(6 \%)$ & $12(3 \%)$ & 0,49 \\
\hline Anxious Hypochondriacal & $6(2 \%)$ & $18(5 \%)$ & 0,44 \\
\hline Harmonious Ergonomic Anosognosic & $114(30 \%)$ & $60(16 \%)$ & 0,03 \\
\hline Harmonious Anosognosic & $18(5 \%)$ & $6(2 \%)$ & 0,44 \\
\hline Ergopathic Anosognosic & $12(3 \%)$ & 0 & 0,24 \\
\hline Anosognosic Hypochondriacal & 0 & $6(2 \%)$ & 0,48 \\
\hline
\end{tabular}

The analysis of coping patterns established that the predominant positive coping strategies in patients with high therapy adherence included problem-solving planning, self-control and taking responsibility $(p=0,005)$. Interestingly, patients who controlled blood pressure and who gave up smoking commonly demonstrated distancing coping (a negative coping strategy), compared with those who were not adherent to therapy $(p=0,01)$.

The correlation analysis between patients' perception of illness and adherence to treatment have reported the presence of positive correlations between neurasthenic perception model and blood pressure level $(\mathrm{r}=0.30 \mathrm{p}=0.001)$, anosognotic perception model and elevated BMI $(\mathrm{r}=0.30 \mathrm{p}=$ 0.03). A negative correlation between harmonious perception model and systolic blood pressure values $(\mathrm{r}=-0.30 \mathrm{p}=0.001)$ has also been determined.

This correlation analysis of coping strategies and adherence to treatment allowed identifying negative relationships between problem solving planning (a positive coping strategy) and the BMI value after CABG $(r=-0.30, p=0.02)$ and blood pressure values $(r=-0,30, p=0.004)$, between taking responsibility and systolic blood pressure values $(r=-0.30, p=0.0001)$, seeking social support and BMI $(\mathrm{r}=-0.30, \mathrm{p}=0.001)$, and positive relationships between distancing and LDL 
levels $(\mathrm{r}=0.30, \mathrm{p}=0.001)$.

\section{Conclusions}

The present study was conducted to identify psychological predictors of adherence to treatment among patients undergoing coronary artery bypass surgery.

The wide prevalence and elevated incidence of chronic physical illness represents a serious medical and psychosocial problem. The relevance of studying the psychological status of patients with coronary artery disease is associated with the need to develop specific bundles able to improve patients' adherence to therapy. Therefore, the definition of psychological risk factors of nonadherence should be introduced into the routine clinical practice. The problem of studying patients' perception of illness and coping skills of cardiac patients is driven by the lack of evidence, particularly those related to patients' adherence to treatment [7].

We found that about half of the patients before CABG smoked, and only a small percentage of them quitted smoking after the surgery. The number of obese patients after CABG did not change. However, about $20 \%$ of patients achieved the target LDL levels. The number of patients who achieved the compensation of arterial hypertension during six months after CABG did not change significantly (from $62 \%$ to $68 \%, \mathrm{p}=0.4$ ).

We found that patients who were adherent to prescribed treatment (quitted smoking, achieved the target BMI and blood pressure values, were adherent to medical therapy) had, harmonious and ergonomic illness perception model, and those who were not adherent - anosognotic illness perception model. However, this trend was not observed among patients who achieved the target total cholesterol levels, which may be explained by more complex requirements for controlling lipid profile or insufficient patient education [8,9].

Zelenskaya et al. (2011) indicated the prevalence of adaptive (harmonious, ergonomic and anosognotic models) perception of illness among cardiac patients of the same profile, accounting for $80 \%$ of the total cohort [10]. The obtained results were also consistent with previous data presented by M.V. Yakovleva et al. for the Russian cohort of patients. They reported high prevalence of harmonious, ergopathic and combined illness perception models among adherent patients [2].

Positive coping strategies in patients who were adherent to therapy commonly included problem solving planning, self-control and taking responsibility. However, distancing was used by both, patients with high and poor adherence to treatment. Distancing was not the primary coping strategies used by the patients, but was secondary to elective cardiac surgery. After the CABG, this group of patients could switch to another coping strategy, which had a positive effect on their adherence. Among patients with poor adherence to therapy, the main coping strategy was avoidance coping. The presented data are consistent with the results presented by Strokovoy E.A. et al., who demonstrated the presence of associations between avoidance coping and poor patients' adherence to treatment [11].

The correlation analysis between patients' perception of illness and their adherence to treatment established that harmonious illness perception was negatively correlated with blood pressure values, anosognosic illness perception positively correlated with BMI values, and neurasthenic - positively correlated with blood pressure values.

We also found that patients who used problem solving planning, self-control and seeking social support as coping strategies were better at controlling their weight, compared with those who did not use them. In addition, patients who prefer problem solving planning better monitored their blood pressure. Distancing showed the positive relationship with LDL levels, which may indicate the insufficient attention of this group of patients to the control of cholesterol levels. 
The assessment of the psychological status, combining patients' perception of illness and coping skills of patients referred to elective coronary artery bypass grafting allows identifying the predictors for non-adherence to non--medical and medical therapy in the postoperative period. The data prove the need for psychological rehabilitation of cardiac patients. Being introduced into the multidisciplinary rehabilitation framework, it will improve patients' adherence to treatment, resulting in the better quality of life and improved prognosis of patients after CABG.

\section{References}

[1] Chowdhury R., Khan H., Heydon E., Shroufi A., Fahimi S., Moore C., Stricker B., Mendis S., Hofman A., Mant J., Franco O.H. (2013) Adherence to cardiovascular therapy: a meta-analysis of prevalence and clinical consequences. Eur Heart J. 34 (38), 2940-2948. doi: 10.1093

[2] Iakovleva M., Lubinskaya C., Demchenko E., (2015) Internal Picture of the Disease as a Factor of Adherence to Treatment after Coronary Bypass Surgery. Bulletin of the South Ural State University. Ser. "Psychology", 8 (2), 59-70.

[3] Semenova O., Naumova E., Schwartz Y. (2014). Adherence to long-term treatment of cardiovascular disease and non-compliance with medical recommendations: the opinion of patients and physicians by the results of focused interview. Rational Pharmacotherapy in Cardiology, 10(1), 55-61. doi: 10.20996/1819-6446-2014-10-1-55-61

[4] Naumova E., Semenova O., Strocova E., "Adherence to long-term treatment estimation as intentional and unintentional actions," Innovations in Science: Sat. Art. By mater. XV Intern. Scientific-practical. Conf., 2012.

[5] Vasserman L., Iovlev B., Karpova Je., Vuks A. (2005) Psychological diagnostics relationship to disease: manual for doctors. SPb.: SPb NIPNI im. V. M. Behtereva, 32.

[6] Vasserman L., Iovlev B., Isaeva E., Trifonova E., Shhelkova O., Novozhilova M., Vuks A. (2009) Methods for the psychological diagnosis of coping with stressful and problematic situations for a person : Handbook for doctors and medical psychologists. SPb.: NIPNI im.V. M. Behtereva, 38.

[7] Elfimova, E. (2009). Personality and illness: "internal picture of the disease", quality of life and commitment. Zamestitel' glavnogo vracha, 11, 18-25.

[8] Ginzburg M., Kutishenko N., Martsevich S., Fokina A., Daniels E., Zaharova A. (2012). The analysis of factors influencing the terms of hospital admission in patients with acute coronary syndrom (according to the LIS study data - Lyubertsy study on mortality rate in patients after acute myocardial infarction). Rational Pharmacotherapy in Cardiology, 8(2), 141-148.

[9] Lukina Yu., Ginzburg M., Smirnov V., Kutishenko N., Martsevich S. (2012). Treatment compliance, in patients with acute coronary syndrom before hospitalization. The Clinician, 2, 41-49.

[10]Zelenskaya I., Lubinskaya C., Velikanov A., Demchenko E. (2011). Psychological characteristics of patients undergoing coronary bypass surgery, depending on their commitment to participate in a rehabilitation program. Bulletin of the South Ural State University. Series "Psychology", 15(42), 73-76.

[11] Strokova E., Naumova E., Semenova O., Shwartz Yu. (2014). The problem of adherence to long-term treatment of patients with cardiovascular diseases. The International Medical Journal, 4, 20-26. 